\title{
A TEOLOGIA, O FEMININO
}

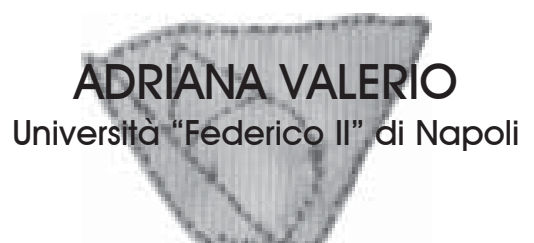

Resumo: O artigo retrata exemplos de mulheres e místicas que leram a Bíblia de uma forma nova e diferente de como a secular tradição masculina fez. Elas conseguiram reinterpretar sua experiência de fé com palavras originais e manifestam uma subjetividade cheia de dúvidas expressa sabiamente pelo uso da ironia. São elas: Domenica Narducci da Paradiso (+1553), que comenta com grande coragem a famosa proibição paulina "As mulheres calem em assembléia" (1Cor 14,34); Arcangela Tarabotti (+1652), que sem temor denuncia o escândalo dos enclausuramentos forçados; Sarah Grimké (+1873), que leva adiante uma leitura emancipacionista e igualitária das Sagradas Escrituras; Elisa Salerno (+1957), que encontra na má interpretação da Bíblia os fundamentos da exclusão feminina e acusa a lgreja Católica de "heresia antifeminista". O rastro de pensadoras nunca se exauriu e retoma vigor nos dias atuais com os estudos e as reflexões de teólogas que impulsionam suas igrejas a buscar novos modos de viver a igualdade e a diversidade, com o intuito de reconhecer na diversidade um valor imprescindível para a fé no Deus Uno e Trino.

Palavras-chave: mulheres e Sagradas Escrituras, mulheres e mística, Deus no feminino.

No início de 1500, uma mulher, Domenica Narducci da Paradiso, célebre em Florença por sua capacidade de interpretar as Sagradas Escrituras, inicia sua atividade de pregadora, um papel tradicionalmente não permitido à mulher, a qual nec predicare nec docere debet $^{1}$ (não deve pregar nem ensinar). Como justifica, então, a legitimidade de sua fala com autoridade?

Em 1507, na presença da comunidade dos discípulos, entre os quais se encontrava também o seu confessor e padre espiritual, Domenica comenta o trecho de São Paulo "As mulheres se calem na assembléia" (1Cor 14,34). A insólita interpretação que Domenica dá ao trecho Ihe suscita perplexidades, logo dissipadas por uma visão: aparece-lhe em sonho São Paulo em pessoa, mandado pelo Esposo, isto é, Cristo, para confortá-la. Ela não deve se preocupar pelas coisas que disse:

fazendo as mulheres estrépito na Igreja, de maneira que parecia quererem pregar, eu [Paulo] as admoestei para que na Igreja calassem; não admoestei que calassem por desprezá-las ou por repreendê-las, ou para proibir-lhes inteiramente a pregação, porque elas são criaturas do Senhor, das quais o Senhor pode se servir como de seus instrumentos,

Copyright $\odot 2005$ by Revista Estudos Feministas

' Adriana VALERIO, 1992. 
do jeito que preferir, da mesma forma que se serviu da obra de uma mulher quando assumiu carne humana.

Se Deus se serviu de uma mulher para encarnar-se, da mesma maneira se serve das mulheres para fazer grande a lgreja, não só pela pregação. Por outro lado, o Espírito sopra onde quer.

Eu, com aquelas palavras - continua São Paulo -, não pretendia fazer resistência ao Espírito Santo, nem poderia fazê-lo, porque ninguém pode resistir ao Espírito Santo. Eu não tive intenção, com aquelas palavras, de proibir a pregação a quem quer que seja; pelo contrário, disse que ninguém deve calar ou falar sem respeito daquilo que o Senhor fazia dizer [...] Depois de mim houve muitas mulheres, as quais, cheias de Espírito Santo, têm pregado. A vida e a doutrina delas são conhecidas na santa Igreja e suas almas são bem-aventuradas na glória do Céu [...] Aliás, depois de mim muitas foram as mulheres que tornaram a Igreja conhecida por suas palavras.

Os teólogos e os homens de lgreja têm, portanto, interpretado mal as palavras do Apóstolo, forçando seu significado e deturpando suas intenções:

... eles insistem naquelas palavras com as quais admoestei as mulheres para que calassem, porque eles as interpretam perversamente e se esquecem das coisas que falei contra os vícios e os pecados [...] Esses homens gostariam de profetizar sem escopo nem trabalho, mas ao contrário andam à caça do louvor humano, desejando tão-somente receber honras. Esses teólogos lêem, estudam, enchem seu cérebro de certas questões sutis, pelas quais dão a entender que sabem e que compreendem muito bem, embora não saibam e não entendam nada.

Deus, ao contrário, escolhe as coisas julgadas fracas e inermes - como as mulheres - para confundir os fortes: São Paulo cita a si próprio (1Cor 1, 27-29). Desse modo, nas mesmas Escrituras, Domenica encontra os elementos para rebater a interpretação tradicional: as mulheres não devem calar, mas antes falar e pregar, porque o próprio Senhor quer que elas, através da humildade e do amor, confundam e redimensionem a suposta sabedoria dos homens de Igreja, os quais, somente pelo conhecimento intelectual, se arrogam o direito exclusivo de falar sobre Deus e de possuir a verdade.

Tal episódio, tantas vezes por mim citado, exprime com clareza dois elementos de história da teologia normalmente desconsiderados: a mulher foi objeto, mas também sujeito de reflexão teológica, além de intérprete de específica sensibilidade. Tal consciência deveria levar a avaliar diversamente os livros em uso em escolas e universidades (manuais de história, de filosofia, de teologia...), nos quais normalmente a presença feminina é quase completamente ignorada, e a admitir uma leitura das fontes que possuímos com os olhos atentos às mulheres: elas não são mais, ou só objeto passivo de pregação e doutrinação.

A valorização de sua presença na história e, especificamente, na tradição cristã redesenha, portanto, a trama e o enredo de um tecido cultural muito mais amplo e articulado, que coloca o masculino e o feminino em espaços de mútuas trocas e enriquecimento; a mesma escrita feminina - que até o século XIX foi de caráter quase exclusivamente religioso - devolve à hodierna leitura crítica mais atenta às assim chamadas diferenças de gênero um matizado panorama de sensibilidade e de abordagens interpretativas que enriquecem certamente a tradicional cultura teológica. Mártires, viajantes, poetisas, visionárias, pedagogas, místicas, pregadoras, narradoras, profetisas, fundadoras, rainhas, abadessas, beatas nos legaram um patrimônio de experiências e de testemunhos - a ser ainda explorado - de extrema riqueza e profundidade. O conhecimento

${ }^{2}$ Rita LIBRANDI e Adriana VALERIO, 1999, p. 157. 
de seu pensamento curaria o desequilíbrio que reinou durante séculos, redimensionando a presunção dos varões que se consideram os únicos, confiáveis intérpretes do mundo e de Deus. ${ }^{3}$ teológica:

Podem-se assinalar duas modalidades de participação das mulheres na elaboração

a. Mulher e subjetividade crítica. No momento em que Arcangela Tarabotti escreve O inferno monacal (1650), ela manifesta em toda a sua dramaticidade um sistema-aquele dos enclausuramentos forçados - mediante os quais se relegavam as mulheres a lugares de aniquilamento e de mortificação. ${ }^{4}$ Semelhante denúncia a encontramos novamente em outras de suas obras (Paraíso monacal, de 1643, Defesa das mulheres, de 1651, e Simplicidade enganada, póstumo, de 1654), nas quais a escritora veneziana associa, mesmo sob ângulos diferentes, a uma sátira contundente contra a tirania paterna, o grito de liberdade das mulheres. As Sagradas Escrituras, relidas com olho crítico, servem a Tarabotti para desmascarar muitos preconceitos, devolvendo à mulher uma reencontrada dignidade.

O fio de uma subjetividade cheia de dúvidas atravessa a ironia feminina em muitos lugares da literatura religiosa; não é o caso, aqui, de deter-nos em tudo: o importante é ter presente que a Bíblia representa o instrumento principal pelo qual é possível reler criticamente a tradição e o pensamento teológico.

Fez-se referência ao Novo Testamento [...] mas devo elevar meu protesto contra a errônea tradução de alguns passos por parte dos homens que fizeram aquele trabalho e contra a interpretação deformada dos homens que em seguida assumiram a tarefa de comentálos. Inclino-me a pensar que, quando nós formos admitidas à honra de estudar o grego e o hebraico, daremos versões da Bíblia um pouco diversas daquelas que temos. ${ }^{5}$

Assim se exprimia Sarah Grimké, quando em 1837 respondia ao clero congregacionista de Massachusetts, severo censor das mulheres que ousavam falar em público.

A leitura de Grimké assinala como o vasto projeto da Women's Bible é ponto de confluência de diversas linhas convergentes; no final do século XIX, esse projeto verá algumas mulheres da América do Norte, reunidas em torno da figura de Elizabeth Cady Stanton, aplicarem-se na análise crítica dos sagrados textos para desconstruir os pressupostos patriarcais que a tradição anti-emancipacionista ou anti-igualitária havia construído. ${ }^{6}$

"Chegou a hora para nós mulheres de ler e interpretar a Bíblia por nós mesmas", havia afirmado Mrs. Cutler, em 1854, à Convenção americana pelos direitos das mulheres em Philadelphia. Ainda, em torno de Virginia Broughton, foram se formando grupos de mulheres chamados Bible Bands, aos quais a leitura das Escrituras, freqüentemente ainda ingênua, fornecia os instrumentos para uma crítica às Igrejas e as motivações em vista de um envolvimento social mais consciente. ${ }^{7}$

Na Itália, não obstante o pesado clima da igreja pós-unitária e o pouco conhecimento da Bíblia por parte dos fiéis, não faltam interessantes casos de análise dos

\footnotetext{
${ }^{3}$ VALERIO, 1985 e $1990 a$

${ }^{4}$ Arcangela TARABOTTI, 1990.

${ }^{5}$ Sarah GRIMKÉ, 1990, p. 58. Pertencente à igreja episcopal antes e depois à quacre, Grimké empenhou-se, junto à irmã Angelina, na luta anti-escravagista. As suas Letteres foram julgadas "a melhor obra depois dos Diritti delle donne (Direitos das mulheres) de Mary Wollstonecraft" (Judith NIES, 1977, p. 78).

${ }^{6}$ STANTON, 1974. Há um perfil biográfico de Stanton em Anna ROSSI-DORIA, 1990, p. 122-126. Sobre a relação mulher-Bíblia: Claudio LEONARDI e Adriana VALERIO, 2002.

${ }^{7}$ Virginia BROUGHTON, 1988, p. 40 et seq. Cf. Cristina MATTIELLO, 1993. No mesmo contexto americano, Sojourner Truth (a escrava Isabella), que nas Escrituras havia encontrado os pressupostos para legitimar a
} 
textos sagrados. Em 1926, Elisa Salerno publicava em dois volumes os Comentários críticos às notas bíblicas antifeministas dos primeiros 24 livros sagrados, isto é, do Gêneses aos 4 Sapienciais, inclusive, encontrando nas Escrituras, ou melhor, em sua má interpretação, os fundamentos daquela exclusão feminina que tão duramente havia caracterizado a história humana. Em sua releitura das Escrituras, Salerno sabe colher aqueles elementos de novidade representados pela forte presença feminina na história da salvação ou pela mensagem de Jesus que liberta as mulheres do âmbito da marginalidade, devolvendo-lhes uma autêntica dignidade: mensagem não atendida, traída pela Igreja, assim como Salerno denuncia, tanto que define como "heresia antifeminista" a visão sobre a mulher transmitida pela cultura católica. ${ }^{8}$

O percurso exegético, em suas repercussões político-eclesiais, pode ser reconstruído pela história da exegese de alguns passos que marcaram fortemente identidade e papéis sexuais. Refiro-me às tentativas de reler a Bíblia não mais para justificar a exclusão ou a subordinação das mulheres, antes para encontrar nela o fundamento da valorização do universo feminino, para o seu maior reconhecimento no âmbito eclesial e social. O papel encarnado por Eva na economia da salvação (criação e queda), de um lado, e a proibição dada por São Paulo às mulheres da comunidade de Corinto de se pronunciarem em qualquer caso com palavra de autoridade constituem os textos fundamentais que inspiraram as estruturas dos sistemas eclesiástico e político. A leitura distorcida de tais textos excluiu o sexo feminino da visibilidade institucional, relegando-o tão-somente ao exercício de papéis subordinados. Paralelamente a uma esmagadora tradição exegética, é possível reatar os fios de uma leitura tênue, talvez, mas constante, feita por algumas mulheres que souberam colher na palavra bíblica uma ocasião para ganharem força e consciência de si, graças a novas perguntas postas aos textos que elas julgavam interpretados erroneamente pela tradição exegética.

O retrato de Eva e a reflexão sobre o ser imago Dei, como os reencontramos nos textos de lldegarde de Bingen, de Cristina de Pizzano, de Isotta Nogarola, de Lucrezia Marinella, de Marie de Gournay... se afastam daquele modelo negativo e inculpador que o pensamento teológico consignou às nossas consciências. ${ }^{9}$

Também a interdição paulina ("As mulheres calem em assembléia") tornou-se, nas reflexões de Domenica da Paradiso, de Arcangela Tarabotti, de Juana Ines de la Cruz, de Margaret Fell, de Sarah Grimké, de Elisa Salerno, da hodierna crítica feminista - mesmo se em diferentes contextos históricos e culturais -, motivo de reflexão sobre a relação entre a palavra textual, o contexto histórico e a subjetividade interpretativa; isso permitiu a elaboração de novas hipóteses que abrem para a participação da vida pública.

b. Mulher e especificidade de gênero. Não é sempre fácil identificar a especificidade dos percursos de reflexões que, mesmo diversificadas, foram codificadas pelas academias, até porque a tradicional antropologia teológica conhece uma uniformidade de leituras que homologam em papéis hierárquicos, separados e estereotipados, o masculino e o

libertação da escravidão, havia conseguido, com base em sua própria vivência, envolver também outras mulheres no projeto comum de libertação das muitas formas de sujeição. Para Sojourner Truth, se Eva foi capaz de revirar o mundo, as mulheres também devem ser capazes de fazer o mesmo (MATTIELLO, 1993, p. 25). Sobre ela, ver também Gabriella LAVINA, 1999.

${ }^{8}$ Desta forma Salerno definirá a heresia antifeminista: "A heresia antifeminista ou antifeminismo católico [...] é aquele conjunto de erros, de mentiras, de injustiças que tem como alvo a exclusão, a degradação, o detrimento, o desprezo da mulher, por ser mulher. Todos os preconceitos antifeministas [...] espalhados pelo mundo contra a mulher [..] são substancialmente afirmados nos livros dos homens de igreja" (M. PASINI, 1948 , p. 6). Sobre Salerno: Elisa VICENTINI, 1995. Para conhecer diretamente seu pensamento: SALERNO, 2002.

${ }^{9}$ Elisabeth GOESSMANN, 1984 e 1988, p. 190 et seq. Sobre imago Dei: Kari E. BOERRESEN, 2001. 
feminino. O que acontece, então, quando as mulheres iniciam a escrever e a comunicar a própria experiência de fé, a própria percepção de Deus?

A elaboração do pensamento afunda as raízes no corpo. Não falo do corpo negado, que tanta parte tem na literatura mística feminina, herdeira daquela depreciação da natureza fisiológica que caracteriza a nossa cultura ocidental cindida; entendo, antes, o corpo como lugar de especificidade e de subjetividade, do qual não se pode prescindir e do qual se origina a elaboração das metáforas para "dizer Deus".

Analisando certos escritos religiosos femininos compreendemos como, partindo da corporeidade e utilizando os códigos do feminino, as mulheres podem mudar a percepção de si e, sobretudo, criar novas metáforas que enriquecem a imagem de Deus.

Deus não é mais, e somente, Pai, Filho, Espírito, Juiz, Esposo, mas também Mãe, regaço, seio, comida, leite, fonte, Sabedoria, senhora, Amor.

Um Deus de múltiplas faces: pai acolhedor, mãe que nutre, esposo para amar, criança para cuidar, companheiro de viagem, dona de e da casa que convida ao banquete, mulherjuiz, amiga sábia que liberta.

Deus Pai, Filho, Espírito é declinado no feminino como Deus Mãe, Compaixão, Sabedoria. Alguns escritores cristãos já haviam percebido a complexidade do mistério divino lido em chave de "gênero", diríamos nós hoje. Para Clemente de Alexandria,

o próprio Deus é amor e a causa deste amor tornou-se visível para nós. Seu ser indizível o torna Pai, sua compaixão por nós o torna Mãe. O Pai amou e foi mulher. O grande sinal é que gerou de si mesmo. E o fruto nascido deste amor é amor. ${ }^{10}$

Agostinho de Hipona havia atribuído a Cristo paternam auctoritatem e maternum affectum, ${ }^{11}$ tema devocional retomado pela literatura espiritual da mística cisterciense, desde Anselmo até Bernardo de Claraval e a Guerrico de São Quintino (+1245). Segundo este último, Deus enquanto Mãe aponta para seu papel misericordioso:

Aquele que é pai porque criador da natureza ou porque nos regenerou com a graça ou também pela autoridade com a qual nos guia, seja também mãe pelo afeto cheio de clemência e seja nutriz pela assiduidade e pela atenção com as quais cuida de nós. ${ }^{12}$

Com a reflexão das mulheres, todavia, muda alguma coisa: a maternidade não é mais aspecto devocional útil a mitigar a masculinidade de Deus; ela se torna um dado teológico, constitutivo da essência de Deus. ${ }^{13} \mathrm{~A}$ maternidade é propriedade que convém a todas as três pessoas da Trindade. Para Matilde de Hackeborn (+1298), Cristo é pai na criação, irmão no Reino, mãe na redenção, sendo a maternidade atributo essencial da divindade. ${ }^{14}$

Toda a Trindade, modelo paradigmático de um dinâmico revelar-se de Deus no plano histórico, é declinada no feminino. Para Hadewijch de Antuérpia (+1240), a escritora beguina dos Minnesaenger, os cantos do amor, o divino é a Senhora Amor (die Frau Minne), amor absoluto, amor-desejo.

No primeiro princípio Amor (Die Minne) nos sacia:

quando Amor no início me falou de amor,

${ }^{10}$ CLEMENTE DE ALEXANDRIA. Quis dives salvetur. 37,1-2 (GCS 17, 184).

"AGOSTINHO. Enarrationes in Psalmos, $101,1,7$ (Corpus Christianorum 40, 1431-32). E, ainda, Agostinho dirá que Deus "pater est, quia condidit, quia vocat, quia iubet, quia regit; mater quia fovet, quia nutrit, quia lactat, quia continet" $(101, \mathrm{l}, 8)$. Cf. BOERRESEN, 1993.

${ }^{12}$ GUERRICO DE S. QUINTINO. Sermo 2,2 (PL 185,181).

${ }^{13}$ Giovanni POZZI, 1988.

${ }^{14}$ MATILDE DI HACKEBORN. Liber specialis gratiae, II, 16. Cf. Peter DINZELBACHER, 1994, p. 229 et seq. 
Ahi! Como toda a Ele, de tudo eu ria: fez-me então assemelhar-me à semente que na cinzenta estação logo floresce mas longamente o fruto faz esperar.

Um Amor, Deus em pessoa, de gênero feminino também no francês de mil e duzentos (Dame Amour), como o encontramos no escrito de Margherita Porete (+1310), Lo specchio delle anime semplici (O espelho das almas simples), por causa do qual ela foi queimada na fogueira. Em sua reflexão, a desafortunada beguina transfere para a linguagem vernacular uma experiência de Deus concebido não na ordem do poder, mas na ordem do amor/ cortesia/caridade. ${ }^{16} \mathrm{O}$ movimento do Livre Espírito que dela procede tentará percorrer o caminho de um amor-Espírito que liberta dos poderes:

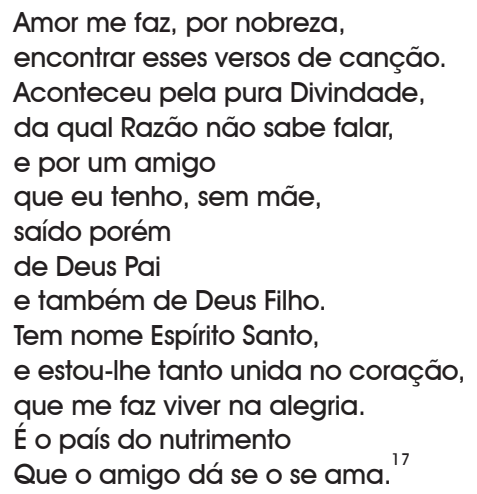

A um Deus-Ser (que, por ser alteridade, incute sujeição ao homem), Margherita prefere um Espírito/amor, supremo Amigo da alma.

Alguns anos antes da morte de Porete, sabemos da existência de uma comunidade reunida em torno de Guglielma de Milão (+1280), venerada como encarnação do Espírito Santo. ${ }^{18}$ Guglielma havia reunido à sua volta crentes em constante escuta de suas palavras inspiradas e quando da sua morte, segundo a natureza humana, havia designado uma discípula, Maifreda, como sua vigária. Ela, de fato, por ser encarnação do Espírito Santo, iria subir ao céu, no Pentecostes de 1300, na presença de seus discípulos, para elevar as mulheres e para instaurar uma nova Igreja com hierarquia feminina. Maifreda, na espera de ser eleita papisa, pregava, exercitava poderes sacerdotais, fazia-se chamar Vigária solicitando de seus seguidores gestos de obséquio usualmente reservados ao papa. Nessa história de heresias, que se conclui em 1302 com a condenação à fogueira não somente dos discípulos da mulher, mas até do próprio corpo de Guglielma (morta em 1280!), emerge o anseio pela edificação de uma Igreja no feminino. Na elaboração teológica da comunidade que a ela se refere, o feminino de Deus encontra a própria tradução visível e histórica em uma Igreja-Instituição governada por mulheres. Um capítulo importante da historiografia das heresias: um sonho, mas também um incômodo profundo que questiona a teologia em suas articulações teóricas e em suas traduções práticas. Podem as mulheres

${ }^{15}$ HADEWIJCH DI ANVERSA, 2000, p. 13.

${ }^{16} \mathrm{C}$. PORETE, 1994.

17 PORETE, 1994, p. 443.

${ }^{18}$ Adriana VALERIO, 1990b; Marina BENEDETTI, 1998. 
considerar-se redimidas por um Deus Homem-varão e sentir-se representadas por uma comunidade eclesial regida só por varões?

Para Giuliana de Norwich (+1420), a maternidade, The Motherhood in God, representa a plenitude de Deus em criar, redimir e chamar o mundo à liberdade. Igualmente, também Jesus Cristo "é a nossa verdadeira Mãe", que nos nutre e não permite que morramos, porque o amor da mãe é o amor total que não admite derrota.

A nossa verdadeira Mãe, Jesus, ele somente nos gera para a alegria e a vida eterna [...] Por isso é para ele como uma obrigação nos nutrir, porque o precioso amor da maternidade o fez devedor para conosco. Uma mãe pode dar à criança seu leite para mamar, mas a nossa caríssima Mãe Jesus é capaz de nos nutrir de si mesmo [...] A palavra "mãe", bela e cheia de amor, é em si tão doce e gentil que não pode ser propriamente dita de ninguém e a ninguém a não ser dele e a ele, que é a verdadeira Mãe da vida e de tudo. São propriedades da maternidade o amor natural, a sabedoria e o conhecimento, e isto é Deus. ${ }^{19}$

É o tema de Cristo mãe, desenvolvido no célebre estudo de Caroline Bynum, no qual são apresentados os vários tópicos da mística medieval, em que Cristo é lido como mãe que cuida de nós, que nos nutre e nos salva. ${ }^{20}$

Esses são apenas alguns exemplos de uma presença bastante numerosa, mesmo que freqüentemente isolada, que fala sobre novas possibilidades de fazer teologia, toda vez que o sujeito da reflexão muda: com a mudança do sujeito, mudam as perguntas e, portanto, as respostas. Por isso podemos descobrir, através dos escritos dessas mulheres, modalidades diferentes não somente de narrar Deus (declinado também no feminino, como Paternidade, Maternidade e Sabedoria), mas também de conceber a estruturação da comunidade (visivelmente masculina e feminina) e de viver a fé de forma operativa, encarnando-a (segundo os ditames de uma "ética da solicitude" paralela à jurídica).

A relação das mulheres com a teologia, até chegar aos tempos do Vaticano II, não passou, portanto, por lugares acadêmicos; caracterizou-se, antes, pela experiência mística, sobretudo na idade média e moderna. Hoje deve ser procurada na passagem da tutela à responsabilidade, naquela tensão irresolvida entre a razão crítica, que as mulheres adquiriram em relação às suas Igrejas de pertença, e sua indagação inquieta, a busca por novos modos de redefinir os papéis, e também de viver a fé, a interrogação sobre um renovado relacionamento com o transcendente; entre os pedidos provocatórios de igualdade e os chamados apaixonados pela diversidade; entre a atração pela homologação e a necessidade da auto-significação. ${ }^{21}$

$\mathrm{O}$ acesso das mulheres às faculdades teológicas permite hoje a aquisição de instrumentos aptos a redesenhar competências e a reescrever conteúdos. Seu empenho se joga na capacidade - se quisermos parafrasear as palavras de Virginia Woolf - de

19 GIULIANA DE NORWICH, 1984, p. 256. "Uma mãe pode deixar que a criança caia de vez em quando e sofra diversas dificuldades, e isso para o seu bem, mas não pode nunca permitir, pelo amor que tem por ela, que a criança seja vítima de qualquer perigo. E também se a nossa mãe terrena pode deixar morrer a sua criança, a nossa Mãe celeste, Jesus, não pode nunca permitir que os seus filhos pereçam, porque ele é onipotente, toda sabedoria e amor" (GIULIANA DE NORWICH, 1984, p. 260).

${ }^{20}$ Caroline W. BYNUM, 1982. A Domenica da Paraíso Cristo aparece com os peitos: "Esposa, eu que também sou mãe tenho os peitos cheios de leite; e chamo os meus filhos para que venham mamar o meu leite porque eles estão sempre cheios, transbordando. E os peitos e as fontes que eu tenho são as graças e a minha divindade. Chamo então todos os meus filhos juntos e a eles ofereço os bicos dos meus peitos": Visione del Tabernacolo (Visão do Tabernáculo), ms. f. 28r.

${ }^{21}$ Marie-Thérèse VAN LUNEN-CHENU e Rosino GIBELLINI, 1988. Sobre a declinação de Deus no feminino: Elisabeth A. JOHNSON, 1999. 
encontrar "novas palavras" e inventar "novos métodos" para afirmar a própria diversidade como valor. Estas "novas palavras", estes "novos métodos" devem ser elaborados pelas mulheres, para completar, enriquecer e inovar uma teologia que durante demasiados séculos conheceu somente um olhar que, mesmo poliédrico, foi sempre marcado somente pelo gênero masculino. ${ }^{22}$

\section{Referências bibliográficas}

BENEDETTI, Marina. Io non sono Dio. Guglielma di Milano e i Figli dello Spirito Santo (Eu não sou Deus. Guglielma de Milão e os Filhos do Espírito Santo). Milano: Edizioni Biblioteca Francescana, 1998.

BOERRESEN, Kari E. "L'uso patristico di metafore femminili nel discorso su Dio" (O uso patrístico das metáforas femininas no discurso sobre Deus). In: . Le Madri della Chiesa. II Medioevo (As Mães da Igreja. O Medievo). Napoli: D’Auria, 1993. p. 109-126.

BOERRESEN, Kari.E. (Org.). A immagine di Dio. Modelli di genere nella tradizione giudaica e cristiana (A imagem de Deus. Modelos de gênero na tradição judaica e cristã). Firenze: Carrocci, 2001.

BROUGHTON, Virginia. Twenty Years' Experience of a Missionary. Chicago: Pony Press, 1907. Reimpresso com o título Spiritual Narratives. New York: Oxford University Press, 1988.

BYNUM, Caroline W. Jesus as Mother. Studies in the Spirituality of the High Middle Ages. Berkeley: California Press, 1982.

DINZELBACHER, Peter Christliche Mystik im Abendland. Wien: Ferdinand Shoening Verlag, 1994.

GIULIANA DE NORWICH. Libro delle Rivelazioni (Livro das Revelações). Milano: Editrice Ancora, 1984. XIV Riv., cap. 60-61. Org. por Domenico Pezzini.

GOESSMANN, Elisabeth. "Die Gelehrsamkeit der Frauen im Rahmen der europaeischen Querelle des Femmes." In: . Das wohlgelahrte Frauenzimmer, Archiv fuer philosophie-und teologie-geschichtliche Frauenforschung. Monaco: Iudicium Verlag, 1984. v. 1. p. 7-20.

GOESSMANN, Elisabeth. "La nostra responsabilità per la storia della salvezza. La tradizione dell'interpretazione della Bibbia da parte delle donne" (A nossa responsabilidade pela história da Salvação. A tradição da interpretação da Bíblia por parte das mulheres). In: WALTER, Karin; BARTOLOMEI, Maria Cristina (Orgs.). Donne alla riscoperta della Bibbia. Brescia: Queriniana, 1988.

GRIMKÉ Sarah. "Letters on the Equality of the sexes and the Condition of Woman" (1838). In: ROSSI-DORIA, Anna (Org.). La libertà delle donne. Voci della tradizione politica suffragista (A liberdade das mulheres. Vozes na tradição política sufragista). Torino: Rosenberg \& Sellier, 1990.

HADEWIJCH DI ANVERSA. Poesie, Visioni, Lettere (Poesias, Visões, Cartas). Genova: Marietti Editrice, 2000. Poesia I. Org. por Romana Guarnieri.

LEONARDI, Claudio; VALERIO, Adriana (Orgs.) La Bibbia nell' interpretazione delle donne (A Bíblia na interpretação das mulheres). Firenze: II Galluzzo, 2002.

\footnotetext{
${ }^{22}$ Ao amigo $\mathrm{M}$. Foster que a convidava, fazendo uma exceção, a aderir a um comitê antifascista proibido às mulheres, assim Woolf respondeu: "O melhor modo de vos ajudar a prevenir a guerra não é repetir as vossas palavras e seguir os vossos métodos, mas o de encontrar novas palavras e inventar novos métodos. Não é o de entrar na vossa associação, mas o de permanecer fora dela mesmo compartilhando seus fins" (WOOLF, 1998, p. 188).
} 
LAVINA, Gabriella "'Comunque in terra straniera' La navigazione solitaria di Hariet Tubman e Sojourner Truth" ("Todavia em terra estrangeira". A navegação solitária de Hariet Tubman e Sojourner Truth). In: SILVESTRE, Maria Luisa; VALERIO, Adriana (Orgs.). Donne in viaggio (Mulheres em viagem), Roma-Bari, Laterza, 1999. p. 187-198.

JOHNSON, Elizabeth A. Colei che è. II mistero di Dio nel discorso teologico femminista (Aquela que é. O mistério de Deus no discurso teológico feminista). Brescia: Queriniana, 1999.

LIBRANDI, Rita; VALERIO, Adriana. I sermoni di Domenica da Paradiso. Studi e testo critico (Os sermões de Domenica da Paraíso. Estudos e texto crítico). Firenze: Il Galluzzo, 1999.

MATTIELLO, Cristina. “'I maschi non c'entrano per niente': predicatrici e profete nere nell'America dell'Ottocento." ('Os varões não têm nada a ver': pregadoras e profetizas negras na América de Oitocentos). Acoma, n. 3, p. 24-28, 1993.

NIES, Judith. Seven Women. Portraits from the American Radical Tradition. Dallas: Penguin Books, 1977.

PASINI, M. (pseud. de E. Salerno). II neoantifemminismo (O neoantifeminismo). Vicenza: Arti Grafiche delle Venezie, 1948.

PORETE, Margherita. Lo specchio delle anime semplici (O espelho das almas simples). Tr. Giovanna Fozzer. Milano: Edizioni Paoline, 1994.

POZZI, Giovanni. "L'alfabeto delle sante." (O alfabeto das santas). In: POZZI, Giovanni; LEONARDI, Claudio (Orgs.). Scrittrici mistiche italiane (Escritoras místicas italianas). Genova: Marietti, 1988. p. 21-42.

ROSSI-DORIA, Anna (Org.). La libertà delle donne. Voci della tradizione politica suffragista (A liberdade das mulheres. Vozes na tradição política sufragista). Torino: Rosenberg \& Sellier, 1990.

SALERNO, Elisa. Una penna inquieta. Lettere scelte di Elisa Salerno (Uma pena inquieta. Cartas escolhidas de Elisa Salerno). Padova: Edizioni Messaggero, 2002.

STANTON, Elizabeth Cady. The Woman's Bible. New York: European Publishing Company, 1895. part. 1; 1898. part. 2. Reimpresso com o título The Original Feminist Attack on the Bible. New York, Arno Press, 1974.

TARABOTTI, Arcangela. L'inferno monacale (O inferno monacal). Torino: Rosenberg \& Sellier, 1990. Org. por Francesca Medioli.

VALERIO, Adriana. "La donna nella storia della Chiesa." (A mulher na história da Igreja). Concilium, n. 6/1985-Donne: invisibili nella teologia e nella chiesa (Mulheres: invisíveis na teologia e na igreja), p. 91-101.

VALERIO, Adriana. Cristianesimo al femminile. Donne protagoniste nella storia delle Chiese (Cristianismo ao feminino. Mulheres protagonistas na história das Igrejas). Napoli, D'Auria, 1990a.

VALERIO, Adriana. "Una chiesa al femminile: Guglielma da Milano" (Uma igreja ao feminino: Guglielma de Milão). In: 113-125. Cristianesimo al femminile. Napoli: D'Auria, 1990b. p.

VALERIO, Adriana. Domenica da Paradiso. Profezia e politica in una mistica del Rinascimento (Domenica da Paraíso. Profecia e política em uma mística da Renascença). Spoleto: Centro Studi Altomedioevali, 1992.

VAN LUNEN-CHENU, Marie-Thérèse; GIBELLINI, Rosino. Donne e teologia (Mulheres e teologia). Brescia: Queriniana Editrice, 1988. Editorial de Adriana Valerio.

VICENTINI, Elisa. Una chiesa per le donne. Elisa Salerno e il femminismo Cristiano (Uma igreja para as mulheres. Elisa Salerno e o feminismo cristão). Napoli: D'Auria, 1995.

WOOLF, Virginia. Le tre ghinee. Introduzione di Luisa Muraro. Milano: Feltrinelli, 1998. 


\section{Theology and The Feminine}

Abstract: The essay presents some examples of women and mystics who have read the Bible differently from the age-old male tradition. They have been able to reinterpret their own experience of faith using a new language, showing a doubtful subjectivity skillfully expressed through irony. They are: Domenica Narducci da Paradiso (+1553), who courageously comments on the famous prohibition ofSt. Paul that "Women must be silent in the assembly" (1Cor 14,34); Arcangela Tarabotti (+1652), who does not fear to denounce the scandal of compulsory wows; Sarah Grimké (+1873), who carries out a reading of the Holy Texts in the light of the emancipation and equality; Elisa Salerno (+1957), who characterizes the roots of female marginalization in the tendentious interpretation of the Bible and accuses the Catholic church of "anti-feministic heresy". Such a presence, which has never exhausted itself throughout the centuries, is becoming more and more important today thanks to the studies and the reflection of female theologians, who are pushing their churches into finding new ways of pursuing equality and diversity, acknowledging an absolute need for the faith in the Trinity. Key Words: Women and Holy Scripture, Women and Mystics, God seen in a feminine way.

Tradução de Adriana Tanese Nogueira 